\title{
Captación de plusvalías en el frente de renovación urbana del barrio Pichincha, Rosario - Argentina (2003 - 2010 )
}

Added value collection in the urban renewal front at Pichincha neighbourhood,

Rosario Argentina (2003 - 2010)

Captação de mais-valias na frente de renovação urbana do bairro Pichincha,

Rosário - Argentina (2003 - 2010)

Cintia Ariana Barenboim*
CONICET, Universidad Nacional de Rosario
Juan Ignacio Duarte**
CONICET, Universidad Nacional de General Sarmiento
Nadia Finch ${ }^{* * *}$
Cámara de Diputados de la Nación,
Ministerio de Obras y Servicios Públicos
de la Provincia de Tierra del Fuego
Argentina

\section{Resumen}

El presente trabajo es producto de una investigación realizada en el doctorado en Geografía de la Facultad de Filosofía y Letras, Universidad Nacional de Buenos Aires. Tiene como intención estructurar un conjunto de hipótesis que permita medir a futuro los efectos acaecidos, en términos de renta de suelo, sobre el Frente de Re-

* Cintia Ariana Barenboim:Arquitecta, Máster en Planificación Urbana y Regional, Universidad Nacional de Buenos Aires (UBA). Doctoranda en Geografía (UBA). Becaria del CONICET.Adscripta en Intervención Urbanística (UNR) y docente del curso Nociones urbanísticas aplicadas al mercado inmobiliario, CADEIROS. arq.barenboim@gmail.com

* Juan Ignacio Duarte:Urbanista. Especialista en Políticas de Suelo Urbano en América Latina, Instituto Lincoln de Políticas de Suelos. Doctorando en Ciencias Sociales, Universidad de Buenos Aires. Becario doctoral de CONICET con sede de trabajo en el Instituto del Conurbano de la Universidad Nacional de General Sarmiento. juanignacioduarte@gmail.com

*** Nadia B. Finck: Socióloga. Actualmente se encuentra finalizando la especialización en Planificación Urbano Territorial de la Universidad Nacional de Rosario.Asesora de la Cámara de Diputados de la Nación y Consultora, Ministerio de Obras y Servicios Públicos de la Provincia de Tierra del Fuego. nadiafinck@hotmail.com 
novación Urbana del barrio Pichincha (Rosario). Este venía sufriendo un proceso de construcción intensivo y que posteriormente fue regulado por el Estado.

Para ello se realiza una descripción general del contexto histórico, del Plan Especial aplicado a esa zona, especificaciones particulares y un análisis de las variaciones que ha sufrido el mercado de suelo a partir de la aplicación del mismo.

Palabras claves: normativas urbanas, mercado de suelo, renta diferencial, captación de plusvalías, Rosario.

\section{Abstract}

This paper is a product of research in the $\mathrm{PhD}$ in Geography at the Faculty of Arts, National University of Buenos Aires. It lis aimed to make up a set of hypotheses allowing us to assess future effects occurred in terms of land rent on the Urban Renewal Front in the Pichincha district (Rosario). Such District had suffered an intensive construction process to be later regulated by the State.

In order to do so, a general description of the historical context, of the Special Plan applied to that area particular specifications of such Plan plus an analysis of the changes undergone by the land market since the time the Plan was put into practice.

Keywords: Urban Policy, Land Markets, Differential Rent, Collection of Capital Gains, Rosario.

\section{Resumo}

O presente trabalho é produto de uma pesquisa realizada no Doutorado em Geografia da Faculdade de Filosofia e Letras, da Universidade Nacional de Buenos Aires. Tem a intenção de estruturar um conjunto de hipóteses que permitam medir no futuro os efeitos acontecidos, em termos de renda do solo, na Frente de Renovação Urbana do bairro Pichincha (Rosário). O mesmo já estava sofrendo um processo de construção intensivo e que posteriormente foi regularizado pelo Estado.

Para isso, é realizada uma descrição geral do contexto histórico, do Plano Especial aplicado para essa área, especificações particulares do mesmo e uma análise das variações que o mercado do solo tem sofrido a partir da aplicação do mesmo.

Palavras-chave: normativas urbanas, mercado do solo, renda diferencial, captação de mais-valias, Rosário. 


\section{Introducción}

La ciudad, como fenómeno complejo en su dimensión territorial, enuncia una doble conformación social y espacial y en efecto así lo entendemos. Se expresan espacialmente eventos relativos a las relaciones sociales entre actores, los cuales se guían por lógicas de acción disímiles, en consideración de un posicionamiento en las múltiples estructuras que arman el entramado social. La ciudad, que es el resultado socioespacial del encuentro de un conglomerado de actores, puede ser abordada desde distintos enfoques y escalas. Dichas orientaciones permiten dimensionar y dar cuenta de procesos particulares que encuentran su manifestación en lo espacial.

En este sentido, para comprender ciertos comportamientos del mercado de suelo, elemento imprescindible para el desarrollo de las ciudades, no podemos dejar de considerar a los actores. Los agentes involucrados se presentan en función de sus intereses específicos siendo partícipes de las múltiples dinámicas del mismo.

El Estado, en su carácter de actor legítimo para regular el ordenamiento territorial, los usos de suelo, la planificación urbana-territorial, etc. adquiere un rol especial en tanto puede incidir en la determinación de las “reglas del juego". En efecto, el Gobierno tiene una incidencia decisiva en el mercado del suelo urbano. Su análisis específico es importante no solamente para comprender bien este mercado, sino para abordar un tópico que tiene una gran trascendencia tanto en el desarrollo urbano contemporáneo como en la vida social: la política estatal sobre el suelo. Entendemos que el trasfondo del interés común y público provee a estas actividades el carácter de función pública. Es decir, el Estado es quien se articula como actor responsable de las políticas inherentes a la materia, fijando criterios, objetivos, planes, instrumentos, etc.

El planeamiento territorial se entiende como la articulación que se requiere para entender y conducir los procesos de organización físico-espacial de las actividades y de transformación del medio físico natural y construido (Bervejillo, 2005, p. $3)$. Este encuentra su eficacia según pueda regular y orientar las acciones privadas en términos de su implicancia territorial, articulando la participación de entes públicos, políticos y técnicos, sociales y económicos (Bervejillo, 2005; De Mattos, 2004).

Por otra parte, pero de manera estrechamente vinculada, el mercado, que constituye el escenario donde los actores económicos intercambian mercancías, encuentra expresiones espaciales en la existencia de diferentes valores. Las cuantías se atribuyen al suelo y sus usos, los inmuebles, las infraestructuras, entre otras, las cuales responden a una multiplicidad de dinámicas que las explican.

En el encuentro entre estas dos estructuras, la público-estatal y la de mercado (por inclusión o exclusión), se definen las consecuencias espaciales que las ciudades atraviesan. En particular, parece hallarse un elemento común alrededor del conjunto de problemáticas ligadas a lo urbano: encarecimiento de la vivienda y el suelo, expulsión de la población, segregación de los sectores más empobrecidos hacia los espacios urbanos o periurbanos más desfavorecidos, congestión, etc. 
Tener en consideración esto es fundamental para dar cuenta de la lucha de poder real por la apropiación del trabajo excedente, que a la vez constituye un mecanismo clave de distribución de la plusvalía. Es en esa disputa entre grupos capitalistas y con distintos sectores de las clases dominadas, donde el Estado tiene la potencialidad no exclusiva, no siempre efectiva y eficaz, de intervenir apoyando a unos y, por ende, en detrimento de otros.

Si bien el plan urbano se postula como el instrumento principal de toda la corriente de la organización estratégica post década de 1990, la intervención efectiva en el territorio se realiza por medio de instrumentos parciales que sectorizan o focalizan las áreas y las problemáticas. Las modificaciones que se hacen suelen fijar objetivos que, por lo general, tienden a buscar mejoras en la productividad y competitividad. Lo antedicho genera más y mejores condiciones que posibilitan a los actores económicos un mayor dinamismo en el territorio local, sin dejar de lado lo que sucede en el contexto internacional.

En efecto, por medio de operaciones urbanas, áreas que quedaron relegadas pasan ahora a constituirse como nuevas centralidades modernas, eficientes y funcionales. Este es el caso, por ejemplo, de los planes especiales, que direccionados a un lugar específico de la ciudad, promueven una serie de modificaciones, plausibles de ser receptoras de nuevas y cuantiosas inversiones inmobiliarias. La zona que se hace más apetecible para sectores que no se han intervenido hasta ese momento y que encuentran allí ámbitos que garantizan un incremento de la rentabilidad de sus inversiones, compiten por el acceso a las parcelas. Este hecho reproduce un fenómeno más complejo, pero que encuentra allí una mínima expresión: el incremento de los precios del suelo.

Esas variaciones que, como veremos, pueden ser explicadas solo de manera compleja, y por medio de una serie de factores, promueven la disposición de un escenario particular para los actores interventores. En efecto, los grupos capitalistas competirán por el acceso a estos. Tal vez algunos sectores sociales allí localizados sean expulsados por ese mismo incremento de los precios, mientras que el Estado puede encontrar la posibilidad de aplicar instrumentos de captación de ganancias devenidas de esfuerzos que no ha realizado el propietario del suelo. Esas ganancias, que llamamos plusvalías urbanas son el aumento del precio de la tierra que experimentan los terrenos a lo largo del proceso de urbanización.

Se trata de una valorización que presenta una serie de rasgos específicos: a) beneficia de manera diferencial a los lotes dependiendo su localización en relación a las fuentes de valorización; b) es atribuible a los esfuerzos de la comunidad en general, especialmente a las acciones del sector público,y menos a los que producen los capitales individuales en los lotes regulares; $c$ ) si bien los incrementos de precios derivan de la acción colectiva son apropiados en forma privada por los dueños de los predios. La expresión plusvalías, según esta definición, alude a aumentos de la renta económica del componente tierra y no a la valorización de la edificación (Smolka y Amborski, 2000; Furtado, 2000).

El presente trabajo, sin ser exhaustivo, pretende estructurar un conjunto de hipótesis que posibiliten medir a futuro los efectos acaecidos en términos de renta urbana, que ha tenido la intervención sobre el barrio de Pichincha, particularmente 
su costa, en la ciudad de Rosario. Para ello se realizará una descripción general del contexto histórico, del plan especial aplicado a esa zona, especificaciones particulares del mismo y un análisis de las variaciones que ha sufrido el mercado de suelo.

\section{La renta en el espacio urbano}

El mercado del suelo $y$, en general, el mercado de los bienes inmobiliarios, ocupa un lugar central en la configuración espacial de las ciudades contemporáneas y en su dinámica social y económica. Para la planificación urbana, para su gestión y para distintas acciones que involucran el espacio urbano, parece indispensable tener en cuenta esta dimensión.

De acuerdo con el énfasis que se plantea el rol de la propiedad, la renta será entendida para Lipietz (1974) como un tributo, es decir, la fracción de ganancia que el capital promocional realiza en la producción capitalista de la vivienda y que el dueño fundiario está apto para apropiarse o según Topalov (1979) y Jaramillo (1994) como un sobrelucro; una ganancia superior a la normal, captado por alguien ajeno al proceso de producción y que no tiene su control.

La noción de renta urbana es diferente a la de renta rural. El sentido de la existencia social de la tierra rural es su potencialidad de sostener un ciclo vegetal a partir del cual se estructura un proceso productivo: la agricultura. En la ciudad consiste en soportar un "espacio urbano" donde se entiende el estrecho entrelazamiento de una serie de actividades que hacen posible y (o) potencian la operación de ellas, siendo la tierra apenas un soporte. Para que estas actividades urbanas se puedan desarrollar, es necesario que el suelo sea adaptado y adecuado, es decir, debe ser construido. Lo que se produce en el terreno urbano, y que se consume para las actividades son las edificaciones (Jaramillo, 2003).

En el caso rural la tierra está ligada a un proceso de producción único, la agricultura (articulación simple), mientras que en la ciudad podemos decir que la tierra tiene una articulación compleja (articulación primaria y secundaria). Aparecen dos familias de rentas: las rentas primarias, ligadas a la construcción, y las secundarias, relativas a las actividades o usos. Las dos influyen y se entrelazan para modular los precios de los lotes en la ciudad.A continuación se distinguen a partir de los conceptos del economista Jaramillo (1994, 2003).

\section{I.I. Rentas urbanas primarias}

El hecho de que se refieran a un proceso productivo: la construcción, les otorga una semejanza con las tierras rurales que corresponden también a un proceso lucrativo. Se desarrollan tres modalidades:

\section{Renta absoluta urbana}

Es una renta generalizada que comparten todos los terrenos urbanos, independientemente de sus circunstancias particulares. En efecto, para poder sostener las 
actividades citadinas, se requiere que exista un entrelazamiento espacial con un número muy considerable de otros inmuebles y actividades, también que esté dotada de infraestructura. Su magnitud constituye el nivel mínimo de las rentas de los terrenos y está regulada por la oferta y la demanda. Sobre ella se superpondrán otras diferencias que se explicarán luego, salvo en el caso de los lotes marginales.

\section{Renta diferencial tipo I}

Los terrenos urbanos poseen diversas particularidades en el proceso productivo de la construcción y se consideran en relación a la constructibilidad (referida a ciertas condiciones geomorfológicas de la tierra) y la localización, siendo definitiva en la modulación de las rentas teniendo importancia sobre todo en el proceso de consumo del espacio construido.

\section{Renta primaria diferencial tipo II}

El tipo II es otra modalidad de renta primaria que tiene un papel decisivo en la modulación de la escala de precios del suelo. Se desprende de la diversa intensidad aplicada a los terrenos encarnándose en un fenómeno de gran relevancia: la producción en altura. La acumulación de espacio construido en un mismo lote, multiplica entonces la ganancia excepcional que el capitalista puede obtener, repercutiendo en magnitudes adicionales de renta.

\section{I.2. Rentas urbanas secundarias}

En la ciudad el suelo se destina a una pluralidad de actividades, entre ellas: comercio, vivienda e industria.Asimismo, el espacio urbano no es homogéneo para acoger dichas funciones.A continuación se desarrollarán las distintas modalidades de uso:

\section{Renta diferencial de comercio}

Los capitales comerciales individuales poseen un carácter heterogéneo en el espacio urbano. La sociedad en su conjunto distribuye las diferentes actividades en distintos sectores de la ciudad en un proceso colectivo que no lo determina el comerciante, ni el consumidor. Se reúnen así las condiciones para el surgimiento de la renta diferencial: una ganancia extraordinaria que escapa del control del capital. La competencia entre los rentistas asegurará la conversión de esta ganancia comercial extraordinaria en utilidad.

\section{Renta de monopolio de segregación}

El caso de la vivienda está entrelazado con la renta diferencial, pero con dinámica y características propias. Allí existe otra modalidad que está ligada a un fenómeno especial: la segregación socioespacial. Este último es un rasgo de gran importancia en las ciudades capitalistas y consiste en que los distintos grupos sociales tienden a ocupar 
lugares separados y diferenciados. La renta de monopolio de segregación se refiere a la disposición de pagar, por parte de los demandantes, un sobreprecio por un sitio con una determinada identificación o estrato social.

\section{Renta diferencial de vivienda}

La vivienda está enlazada espacialmente con una serie de valores de uso inmobiliarios que le son complementarios: el lugar de trabajo, los sitios de aprovisionamiento, de esparcimiento, de educación, etc. No todos los terrenos están en las mismas condiciones al respecto. En este caso, la competencia se establece entre los consumidores de vivienda: todos querrán instalarse en los lugares más ventajosos. El propietario de los lotes privilegiados, podrá utilizar esta competencia, para adueñarse de una renta adicional que se compensará hasta obtener los costos en que incurriría si estuviera más alejada.

\section{Renta industrial diferencial y de monopolio}

En la medida de que haya distintas condiciones para la producción industrial en la ciudad, podría surgir una renta diferencial industrial. El desarrollo técnico y social de los medios de transporte y comunicación tienden a homogeneizar el espacio urbano.Así, los costos de producción para un empresario le son prácticamente indiferentes para localizar sus instalaciones. La industria es muy mala competidora de los terrenos y tiende a ubicarse en los lugares residuales. No obstante, el Estado puede reglamentar la implantación del sector, concentrándola en ciertos espacios específicos, pudiendo llegar a ser insuficientes frente a la demanda. En estas circunstancias consigue una renta de monopolio industrial.

\section{Rol del Estado en el mercado de suelo}

El Estado incide sobre la oferta y demanda de tierras urbanas y sobre sus precios a través de diferentes mecanismos y con distintos resultados. Es uno de los actores más influyentes en el mercado inmobiliario y juega un papel clave en el de suelo. A pesar de que en el imaginario colectivo aparece como un agente neutro, es notoria su influencia en los procesos de producción de la ciudad. Aquí realizaremos un breve repaso, siguiendo a Jaramillo (2009) por cada uno de esos roles, particularmente como regulador de las actividades urbanas, que es lo analizado en este trabajo para el caso de la ciudad de Rosario entre 2003 y 2010.

\section{El Estado como agente fiscal}

Entre los diferentes roles que le cabe jugar al Estado en la política urbana, el de agente fiscal es fundamental. En la medida que define cuál será la carga impositiva sobre cada predio, en realidad está influyendo en los precios del suelo. 


\section{El Estado como agente inmobiliario}

El Estado no solo regula la actividad inmobiliaria sino que es propietario de tierras. Pero no solo posee tierras de uso público, sino también algunas factibles de ser apropiables de manera privada. Produce inmuebles de distinto tipo, algunos de los cuales son destinados a su propio uso como oficinas gubernamentales, sedes administrativas, etc.; otros son de uso colectivo (bibliotecas, teatros, sedes de instituciones educativas, culturales, de salud, etc.); e incluso produce inmuebles de uso privado (algunas modalidades de vivienda social, promovidas o construidas directamente por organismos estatales).

Estas operaciones, en la medida que alteran y transforman la estructura urbana, introducen cambios en los precios de los terrenos, y no solo en los lotes desarrollados por el Estado, sino en aquellos que se relacionan espacialmente con estos (Jaramillo, 2009, p. 364). Por lo tanto, como gran propietario de tierras, el Estado puede incidir en el mercado de suelo.

Con frecuencia y sin proponérselo, su accionar tiene un efecto similar al de los grandes especuladores, pues retiene terrenos en cantidades considerables, que son subutilizados o directamente inutilizados. De esa manera contribuye a agudizar la eventual escasez de tierras y a elevar su precio. Es usual que el Estado conserve la propiedad de terrenos que en potencia pueden tener precios elevados, ya que tienen localizaciones privilegiadas. Los retiene no porque busque apoderarse de esos altos precios, sino por otros objetivos (por ejemplo, instalaciones militares muy extensas que eran periféricas y que, con el tiempo, se vuelven centrales, áreas dedicadas a ferrocarriles o a mercados que la planificación decide trasladar o eliminar, etc.).

Lo anterior da pie a que la propiedad de estos terrenos se use para afectar el precio de los terrenos en general. Una de ellas persigue precisamente combatir la retención que eventualmente ejerzan los propietarios privados mediante la oferta masiva de estos terrenos estatales. Esta es la idea detrás de una herramienta explícita que intenta replicar las acciones estatales en otros mercados como el financiero o el cambiario. Allí el Estado regula los precios, ampliando esporádicamente la oferta para combatir la especulación: la misma denominación con la que se le conoce, un banco de tierras revela esta intención.

Implica no solamente que el Estado, en ciertas circunstancias, lleve al mercado terrenos que posea de forma incidental, sino que mediante un organismo especializado en esas labores adquiera terrenos y los ponga a disposición de los compradores cuando escasean los lotes.

\section{El Estado como proveedor de infraestructura, equipamiento y servicios urbanos}

El Estado define qué sectores de la ciudad van a contar con infraestructura y equipamiento y los tipos de servicios que va a prestar en cada uno de ellos. Como en América Latina nuestras ciudades se caracterizan por una construcción incompleta 
en la cobertura de infraestructura y equipamiento urbano, esas diferencias se trasladan a los precios del suelo. Por lo tanto, las zonas con instalaciones se valorizan más que aquellas que no las tienen, jugando el Estado un papel central en los movimientos de los precios del suelo.

El Estado como regulador de las actividades urbanas a través de normas urbanísticas

En tanto define qué uso se puede desarrollar en un terreno y cuál no, está definiendo las actividades y las rentas que soportará ese suelo. La primera gran diferenciación la produce al clasificar el suelo en urbano y rural, con lo cual está definiendo un rango de precios muy diferente según qué categoría le otorgue al mismo. En el ámbito urbano, define cuáles son los usos que podrán desarrollarse en cada terreno $y$, al igual que en el caso anterior, al precisar las actividades que pueden darse está definiendo las rentas potenciales que soportará cada suelo.

Pero además especifica la intensidad de lo que se puede construir en cada terreno, por lo cual está concretando económicamente el precio potencial de ese terreno, ya que el suelo vale según lo que se puede construir en él, siempre y cuando el mercado valide esa posibilidad. Esto significa que para que en cada zona se obtenga la máxima renta potencial definida según los usos y la edificabilidad otorgada por la normativa, el mercado debe demandar terrenos para utilizar la máxima capacidad de construcción permitida.

Como veremos en el caso analizado, es necesario que el mercado demande edificios con la máxima altura permitida por la nueva normativa para que el precio refleje la nueva realidad.

\section{Contexto histórico del barrio Pichincha}

El área de estudio del presente trabajo, que se denomina Frente de Renovación Urbana, se ubica en la costa del tradicional e histórico barrio Pichincha, que hacia fines del siglo XIX, a partir del crecimiento del puerto y la instalación del ferrocarril, comienza espontáneamente a delinearse. En ese entonces, su epicentro estaba constituido por la estación de trenes Sunchales.

Con la aprobación en Argentina de un sistema conocido como "prostitución reglamentada" y el importante desarrollo demográfico y comercial, se propició la instalación de numerosos burdeles en Rosario, particularmente en Pichincha durante el período de 1915 a 1932. Después, con la prohibición de dichos establecimientos, el sector fue abandonando su carácter licencioso para transformarse en un sitio con características de barrio próximo a la estación ferroviaria.

A partir de la década del 60, si bien la evolución intercensal ya venía disminuyendo en Rosario, resulta llamativo su decrecimiento poblacional siendo uno de los sitios con mayor pérdida de habitantes. Pichincha se fue consolidado como un barrio de viviendas ubicado en el macrocentro rosarino, el cual no se distinguía de ningún 
otro. Asimismo, se observó un notorio contraste con el centro de la ciudad donde empezaban a confluir una mayor densidad de viviendas y edificios de gran envergadura (Barenboim, 2010, p. 2).

Desde los 70, a partir de una serie de publicaciones realizadas por los periodistas Zinni y lelpi, Pichincha se construye como lugar mítico, reforzado por la difusión nacional de personajes. Al mismo tiempo se continuó con un proceso de degradación edilicia y urbana importante, con un bajo grado de sustitución de las edificaciones existentes. A partir de la década del 90, el cierre de los ferrocarriles nacionales y la posterior crisis trajeron como consecuencia la desaparición de numerosos locales comerciales e industriales, quedando algunos inmuebles abandonados (Dócola y Múgica, 2006, pp. 4 y 5).

Sin embargo, desde el año 2003, la ciudad de Rosario experimentó un rápido crecimiento de la actividad económica, motivada principalmente por la renta generada en el sector agropecuario.' El nuevo boom inmobiliario llegó con aires de renovación al barrio, iniciándose su período de mayor reactivación, dando origen a importantes inversiones públicas y privadas. Los nuevos usos se vinculan con su rol patrimonial, cultural y turístico. Asimismo, la estructura parcelaria atraviesa cambios físicos. Se presentan procesos de rehabilitación a partir de la restauración de edificios históricos; completamiento de construcciones con bajas densidades y la renovación total a partir de la sustitución edilicia, liderados por el libre mercado.

La situación fue advertida y replanteada por el municipio manifestando la necesidad de un nuevo ordenamiento. En consecuencia, se elabora entre los años 2005 y 2006, el Plan Especial Barrio Pichincha. El documento estaba orientado a la protección ambiental de un área que ofrece buenas condiciones, pero también presenta situaciones de deterioro edilicio y de sus espacios públicos. Sumado a eso, se produce un acelerado proceso de sustitución a partir de numerosos emprendimientos inmobiliarios.

\section{Criterios de reordenamiento urbano del Plan Especial}

Uno de los instrumentos urbanísticos de ordenamiento de escala intermedia que plantea el Plan Urbano Rosario 2007 - 2017 (2008) es el Plan Especial. Dicho documento técnico es utilizado para programar la transformación física y funcional que se propone para un determinado sector de la ciudad, conjunto de parcelas y (o) ámbitos públicos (calles, avenidas, plazas). Además, detalla las particularidades entre las áreas de dominio público y privado.

I Las causas de este proceso se encuentran en los elevados precios internacionales de los commodities agrícolas, la devaluación de la moneda argentina, el establecimiento de industrias de procesamiento y obras de infraestructura. Por otro lado, la falta de confianza en el sistema financiero generada por la crisis de 2001 y las bajas tasas de interés, determinaron la inversión de estos beneficios extraordinarios en la industria de la construcción. Esta última se comportó como un activo financiero produciendo, por un lado, grandes ganancias y por otro, un incremento más que significativo en el precio de los inmuebles. 
El Plan Especial Barrio Pichincha persigue dos propósitos esenciales y complementarios: la protección del patrimonio urbanístico-arquitectónico y la renovación edilicia del área. La normativa propone un ordenamiento especial, que garantice la protección de sus particulares condiciones urbanas y encauce la transformación, orientada esencialmente hacia la reconversión y mejoramiento del sector.

La normativa lo define como un proyecto urbanístico que:

(...) fija la configuración de la red de espacios públicos, el carácter y tratamiento de los mismos, la morfología de los espacios edificables, las características de la edificación, los parámetros básicos de disposición y dimensión de la edificación (...) y los procedimientos y mecanismos de actuación para el sector urbano delimitado como ámbito de aplicación de este Plan Especial (Ordenanza 8.125, 2007, p. 2).

El criterio establecido para su definición pretende alcanzar los siguientes objetivos:

- $\quad$ Preservar las condiciones ambientales y paisajísticas del sitio;

- $\quad$ proteger áreas y (o) edificios de valor patrimonial;

- $\quad$ asegurar la presencia de la vivienda individual en el barrio;

- $\quad$ promover el desarrollo de este sector de la ciudad como un área complementaria de extensión del área central para el uso residencial y de actividades recreativas;

- $\quad$ estimular la reconversión funcional del sector, promoviendo el desplazamiento de depósitos e instalaciones fabriles;

- $\quad$ fomentar la radicación de actividades comerciales y recreativas que contemplen la recuperación total o parcial de las instalaciones existentes;

- $\quad$ reforzar el carácter de los corredores urbanos;

- $\quad$ orientar la sustitución y la construcción de un nuevo frente articulado con Puerto Norte;

estimular el desarrollo de nuevos prototipos constructivos.

Lo antedicho da como resultado una normativa que presenta de forma articulada diferentes políticas de actuación que fomentan los procesos de preservación y transformación, combinando adecuadamente acciones en un sector particular de la ciudad. Al respecto, la Ordenanza 8.125/07 expresa:

I) Políticas de preservación en sectores acotados a través de su definición como Áreas de Protección Histórica (APH), priorizando el otorgamiento de subsidios e interviniendo a través de la obra pública.

2) Políticas de preservación del carácter barrial induciendo la utilización de nuevos prototipos de vivienda en proyectos de atravesamiento de manzana que sin incrementar altura puedan mantener una densidad edilicia apropiada. 
3) Políticas de renovación en sectores donde se considera importante inducir la sustitución de las edificaciones existentes como ser el frente sobre Av. del Valle y Áreas de Reserva (Ordenanza 8.125, 2007, p. 2).

En el marco del Plan Especial se define un área general y tres áreas particulares. Tiene como fin reglamentar alturas máximas y mínimas, factor ocupacional del suelo, usos permitidos, modificación en la línea municipal (en algunos casos), entre otros indicadores urbanísticos. También, se realiza un inventario de edificios de valor patrimonial.

La primera sectorización corresponde al ámbito urbano de aplicación del plan, delimitado por las calles Vera Mújica, Urquiza, Suipacha, Tucumán, Bv. Oroño y Río Paraná. Las segundas se identifican en función de características tipológicas, espaciales, históricas y de localización urbana:

a) Áreas de Protección Histórica (APH): aplica dispositivos de preservación, protección y (o) eventual sustitución en aquellos sectores que contienen en su interior situaciones que interesa proteger. Entre ellas: construcciones de valor histórico y (o) arquitectónico; condiciones particulares en la edificación, la morfología del conjunto edilicio y la composición o el carácter de los espacios públicos. Las APH establecidas son cuatro: ámbito histórico Pichincha, corredor urbano Av. Salta, entorno Casa del Estudiante y calle Jujuy 2.200-2.300.

b) Áreas de Reserva (AR): son aquellas que poseen un valor singular por la concurrencia de condiciones particulares, como tamaño de lote, ubicación urbana y condición dominial. Su definición queda remitida al momento en que se manifieste interés de transformación para desarrollo de proyectos especiales. Las tres AR son articulación Av. del Valle - Av. Francia, entorno antigua cervecería Schlau y articulación Av. Francia - Hospital Provincial del Centenario.

c) Frente de Renovación Urbana (FRU): define el frente en el cual se pretende inducir una profunda sustitución edilicia. Esto es debido a su alto grado de deterioro, obsolescencia de las instalaciones existentes y la inconveniencia de la persistencia de determinados usos. El FRU de las avenidas Rivadavia / DelValle se divide en dos sectores: Av. Rivadavia entre Bv. Oroño y calle Alvear y Av. Rivadavia y Del Valle, entre Alvear y Pichincha (ver plano I).

\section{Indicadores urbanísticos para el Frente de Renovación Urbana}

El Código urbano es el documento donde se establecen las disposiciones reglamentarias para la transformación de la ciudad en cuanto al uso y la división de la tierra, área construible, destino y alturas de edificación. Forma así parte separada del Reglamento de Edificación, que se relaciona solamente con la construcción, alteración, demolición, remoción, inspección y mantenimiento de los inmuebles e instalaciones. Las disposiciones se aplican por igual a las propiedades privadas o del Estado (Código Urbano de la ciudad de Rosario, 1968, p. 5). 
A partir de la promulgación por parte del poder ejecutivo, en enero de 2007, de la Ordenanza $n^{\circ}$ 8.I25 Plan Especial Barrio Pichincha, los indicadores urbanísticos son modificados en este sector. Es decir, la nueva normativa reemplaza al código urbano. $A$ continuación se enuncian los elementos más significativos sobre las características de la edificación (alineación, factor ocupacional, altura), mecanismos de división de suelo y carácter (usos) de los edificios para el Frente de Renovación Urbana. Asimismo, en la normativa hay otros elementos de menor jerarquía que se han regulado como ser las salientes, ochavas, etc., que no son relevantes para el estudio.

a) Alturas: el Frente de Renovación Urbana admite (en el sector I) una altura máxima de 36 metros. En el sector 2, para edificios de perímetro libre se establece una altura máxima de 66 metros, con un frente mínimo de lote de 25 metros de ancho. La altura mínima es de 13 metros en toda la costa.

b) Índice edilicio y factor ocupacional de suelo (FOS): no se aplica índice edilicio. Se fija un valor de FOS máximo de 0,70 para todas las edificaciones en general a excepción de las cocheras en planta baja donde se permite un FOS diferenciado de I. La volumetría edificada quedará regulada por el cumplimiento del FOS establecido y las reglamentaciones vigentes de patio y centro de manzana.

c) Nueva línea municipal: se establece una nueva línea municipal sur de Av. del VaIle, fijada a cuatro metros con 20 centímetros respecto de la actual línea municipal. Se establece otra al sur de Av. Rivadavia fijada a tres metros respecto de la actual línea municipal, en el tramo comprendido entre su intersección con la línea municipal sur de Av. del Valle y la línea municipal oeste de calle Alvear.

d) División del suelo: solo se admite la subdivisión parcelaria prevista por la Ordenanza de Urbanizaciones $n^{\circ}$ 6.492/97 en el artículo 4.2.7 incisos c) "Subdivisión de lotes existentes con edificación" y d) "Subdivisiones para ampliación de lotes". Se permite la unificación de lotes y se incorpora que cuando la unificación conforme un lote sea mayor a dos mil 500 m2 quedará conformado como un área de reserva.

e) Usos: los usos admitidos están relacionados con actividades residenciales y comerciales, administrativas, de servicios, culturales, deportivas, religiosas, educativas, salud y cocheras de guarda de vehículos propios. Los usos no admitidos están vinculados principalmente con industrias y depósitos de cualquier tipo. No se pueden instalar las playas de estacionamiento descubiertas y cocheras para grandes vehículos, salas de velatorio, estaciones de servicios, laboratorios industriales y cualquier otra actividad que manipule productos químicos, tóxicos, inflamables o explosivos.

Los cambios de uso de suelo promovidos por el Estado no necesariamente conllevan al efectivo desarrollo de esas actividades en esas zonas, sino que se requiere de ciertas condiciones del mercado que lo posibiliten. Esto se relaciona de manera intrínseca con el precio del suelo. Es decir, un cambio de normativa no necesariamente genera de manera automática un incremento de los precios por aprovechamiento 
de las rentas potenciales, si la demanda para los nuevos usos no se verifica en la realidad. En el caso de Pichincha es claro que el mercado posibilita el incremento de la actividad comercial en función de la nueva normativa implementada a la que se agrega el proceso de renovación del área.

\section{Implementación de dispositivos para la captación de plusvalías}

Para los edificios de perímetro libre se aplica el "Régimen especial para la autorización de mayor aprovechamiento por incremento de altura", asimilándolo a lo establecido en la Ordenanza $n^{\circ} 7.799 / 04$. En esta, se establece un sistema de recalificación normativa para los lotes frentistas de dos avenidas (De la Libertad y Huerto).

Básicamente establece el pago de una contribución compensatoria a cambio del permiso de edificación de mayor aprovechamiento por incremento de altura sobre una base determinada. En la misma se define como "altura base uniforme" (36 metros medidos desde la cota más alta de cada manzana) a aquella a partir de la cual se aplica el régimen especial. Se fija una altura máxima $(60 \mathrm{~m}$ y $70 \mathrm{~m}$ para dos tipos de lotes frentistas) hasta la cual el propietario puede construir una vez que hace efectiva la contribución compensatoria.

La ordenanza establece que el cálculo de la contribución compensatoria se efectúa sobre el excedente autorizado, haciendo uso de un precio base por metro cuadrado tomando como referencia tasaciones de mercado. De dicho monto, es decir del valor total obtenido de la superficie extra, se aplica un $10 \%$, siendo la actualización del precio base de carácter anual. Resulta interesante destacar que lo recaudado por este canon tiene un destino definido: 50\% parte al Fondo de Preservación Urbanística de Rosario y $50 \%$ para pavimentación de barrios periféricos. Esto evidencia cierta capacidad de redistribución de los recursos generados por la planificación urbana a través de la aplicación de instrumentos de gestión (ver tabla I).

\section{Precios del suelo}

En los últimos años, se han producido innumerables cambios en la comercialización de los diferentes productos ofrecidos en los diferentes submercados (principalmente residencial y comercial) en el barrio Pichincha. Las distintas situaciones económicas del país y de la ciudad, las incertidumbres sociales, las reglamentaciones locales, la tendencia de crecimiento de Rosario hacia el noreste, las nuevas obras de infraestructura, las formas de financiamiento y la relación entre unidades vendidas y demandadas, entre otras cuestiones, han incidido en las modificaciones de los precios.

El barrio Pichincha no presenta características homogéneas. Es una zona que cuenta con todos los servicios, pero exhibe algunas diferencias marcadas: en parte por la apertura de la ciudad al río, su cercanía con el centro, la presencia de la ex estación de trenes Rosario norte rehabilitada y ocupada por la Secretaría de Cultura Municipal, el impacto del desarrollo de Puerto Norte con su conjunto de edificios 
de alta gama, el shopping Alto Rosario, así como el incremento de los locales comerciales y gastronómicos. También merece destacarse la ubicación de las facultades de la Universidad Nacional de Rosario junto con el Hospital del Centenario. Todo esto repercute en los precios del suelo y también de los inmuebles.

El CPN. Daniel Martinucci, titular de GAMA Inmobiliaria y miembro de las comisiones directivas de la Cámara de Empresas Inmobiliarias de Rosario (CADEIROS) y de la Federación Inmobiliaria de la República Argentina (FIRA), menciona en la entrevista realizada que:

(...) prácticamente cada cuadra tiene un precio distinto y a la vez cada inmueble tiene características propias (...). Los lotes sobre la costa poseen un precio más elevado que el resto del barrio, sin embargo tampoco es toda uniforme. Sobre avenida Rivadavia desde Oroño a Rodríguez está más valorizada. Luego, por la presencia de boliches bailables, algunos galpones en mal estado y antigua infraestructura de la ex estación de trenes, el valor comienza a decaer. El Boulevard Francia conserva su valor comercial y residencial, en cambio la avenida Ovidio Lagos no presenta altos precios debido a su mal estado y el elevado ruido, motivo por el cual no es requerida para residencia. El sector cerca de la ex estación de trenes está muy desvalorizado. Las calles Tucumán y Catamarca poseen un alto valor residencial.

En síntesis, se presentan diversas variables que influyen por un lado en el valor de los terrenos y por el otro en el de los inmuebles. Estos últimos soportan la renta del terreno y de la propiedad. Es decir, cada lote cuenta con diversos tipos de utilidades. En primer lugar, la renta absoluta urbana que tienen todos los terrenos; en segundo término, las rentas primarias, siendo mayor la renta diferencial tipo I que la tipo II; y finalmente, sostienen una de las rentas secundarias siendo la más elevada la renta diferencial de vivienda en el área general y la renta diferencial de comercio sobre algunos sectores (ejemplo: avenida Ovidio Lagos o calle Salta).

Cabe destacar que cada terreno soporta potencialmente varias rentas secundarias, aunque solo se manifiesta en el mercado aquella que es la más elevada de todas y que corresponde al uso de la tierra en la que el propietario puede percibir una mayor porción de excedente, con lo cual será ese el uso que tienda a desarrollarse en cada lugar. En efecto, como afirma Jaramillo, "la lógica de los precios del suelo realimenta el proceso de adscripción convencional de usos a los diferentes terrenos de la ciudad" (2009, p. 196).

\section{Costo de los terrenos}

La entrevista efectuada al Arq. Jorge Picasso, presidente de la Subcomisión y Tribunal de Tasaciones de CADEIROS y docente de posgrado del curso de Tasaciones de la Facultad de Arquitectura, Planeamiento y Diseño de la Universidad Nacional 
de Rosario sumado a los estudios de las Guías de Tasaciones Anuales realizadas por CADEIROS (2005 y 2006) y el relevamiento de los avisos de venta de terrenos publicados por el diario La CapitaR, permitieron identificar los distintos valores de los terrenos en el Frente de Renovación Urbana.

A lo largo del período, los precios de los terrenos han tenido cambios sustanciales, como se puede apreciar en la tabla 2.Asimismo, tuvieron una evolución similar a los del resto de la ciudad, es decir disminuyeron hasta el año 2002 para posteriormente comenzar a ascender hasta el año 2010. La mayor parte de los terrenos se encuentran ubicados en los rangos intermedios de precio por metro cuadrado, aunque los terrenos de la zona de la costa muestran, en general, mayores precios.

En síntesis, durante los años 2003 a 2010 los precios promedios pasaron de 300 a 800 dólares por metro cuadrado. Como es sabido, el cambio constante de los precios de la tierra urbana constituye uno de los rasgos más sobresalientes del funcionamiento de estos mercados.

El resultado de las variaciones observables en la superficie son, como afirma Jaramillo, "combinaciones y manifestaciones de al menos tres tipos de movimientos en los precios del suelo que tienen naturalezas diferentes: movimientos estructurales generales; movimientos coyunturales generales y movimientos estructurales particulares” (2009, p. 206). Como es posible prever, el análisis del autor considera para los movimientos de los precios de suelo urbano la conexión de este con aspectos estructurales o coyunturales de la operación de estos mercados y la escala de su incidencia, que puede afectar a la totalidad de los terrenos o estar focalizado en algunos de ellos.

Para el caso que analizamos, podríamos considerar que en primera instancia y respondiendo a movimientos estructurales generales ${ }^{3}$, el precio del suelo ha tendido secularmente al crecimiento, como sucede en casi la totalidad de las ciudades capitalistas. En particular, en el contexto del "boom inmobiliario" que se produjera desde 2003, cuando la economía nacional comenzó a mostrar los primeros signos de rehabilitación luego de la crisis de $200 \mathrm{I}$. En este sentido, podemos interpretar que una de las causas que impactaron sobre las rentas urbanas de la zona de Pichincha, que afectaron y afectan el precio del suelo urbano, es el crecimiento general de la demanda por espacio construido.

En suma, las posibilidades de inversión de capital se orientaron en muchas ciudades argentinas a la construcción, donde podemos encontrar algunos motivos en las ganancias extraordinarias obtenidas por el sector agroexportador, beneficiado por un tipo de cambio favorable y unas condiciones excepcionales del mercado internacional.

3 Jaramillo (2009) afirma que la denominación responde a que este tipo de movimientos afectan a la totalidad de los terrenos de la ciudad y responde a aspectos estructurales de la operación, tanto de la economía capitalista como del mismo mercado de tierras. 
Entre una mayor demanda de tierra para la construcción y la asistencia de los oferentes se produce el incremento de la renta que refleja esa contraposición: la Renta Absoluta Urbana, que es aquella que comparte la totalidad de los terrenos de una aglomeración, y su incremento es uno de los determinantes más relevantes del crecimiento general de los precios del suelo (Jaramillo, 2009, p. 210 ).

La expansión de la ciudad, es decir su crecimiento físico implica el aumento de rentas diferenciales como la Renta Diferencial de Vivienda y la Renta Diferencial de Comercio, las cuales responden al aumento en la magnitud de los desplazamientos necesarios para usar la ciudad. En el contexto de un período de progreso económico, podemos pensar en un incremento de la demanda de tierra por la colocación de capitales en bienes inmuebles por parte de sectores que accedieron a rentas extraordinarias. Este hecho podría también estar relacionado con el descreimiento generalizado en el sistema financiero, particularmente con posterioridad a la crisis de $200 \mathrm{I}$.

Por otra parte, el mejoramiento de los niveles generales de la economía y del empleo posibilitó a algunos sectores a acceder a mecanismos de financiación para el acceso a la vivienda o la inversión en pequeños negocios. La mejora de la situación económica pudo haber repercutido también en el acceso de las nuevas generaciones de las clases medias que se trasladan a la ciudad de Rosario para acceder a estudios universitarios.

En efecto, la migración de muchos jóvenes de localidades cercanas, incluso de provincias vecinas, ejerció una demanda de viviendas para alquiler. El incremento de la Renta Diferencial de Comercio se explica por el incremento del consumo de los habitantes de la ciudad producto del desarrollo de la acumulación que encuentra en el período tratado, con una curva ascendente.

En la zona particular de Pichincha, sin embargo, asistimos a un proceso de crecimiento de las Rentas Diferenciales tipo II, las cuales se incrementan una vez que la magnitud de la renta local (precio de venta) sobre un terreno sobrepasa cierto nivel de altura. Es decir cuando es posible y viable la producción en altura, densificando la zona.

Esto promueve el crecimiento de las rentas urbanas que ya soportaban esos terrenos, puesto que el capitalista invierte un mayor capital por construir con una técnica más intensa, pero se ve recompensado por la reducción en la renta que paga en tanto utiliza proporcionalmente menos tierra. Así, los "aumentos en el precio del espacio construido repercuten de manera más concentrada en aumentos de la renta (...) el ritmo de incremento de la renta se acelera una vez traspasado ese límite" (Jaramillo, 2009, p. 200).

El hecho de que aún no se hayan producido las inversiones correspondientes al mayor aprovechamiento -y en consecuencia no se haya cobrado el canon dispuesto por el gobierno local- puede deberse a una multiplicidad de factores. Mientras no se generalice entre los capitalistas la percepción de la posibilidad de una ganancia excepcional, serán los primeros con capacidad de construir en altura quienes perciban esas ganancias extraordinarias (ganancia adicional). Es decir, que a pesar del cobro del canon, en esta primera instancia, los terrenos se siguen transando a precios que corresponden a la técnica precedente a la construcción en altura. 
Estos factores estructurales sumados a la creación de percepciones sobre la zona como área deseable para la inversión y para el consumo de espacio construido, promueven el crecimiento generalizado de los precios del suelo en el área a que nos referimos. Como puede vislumbrarse, el incremento de los precios de los inmuebles se correlaciona con la existencia de una serie de fenómenos relativos a las condiciones particulares de la zona de Pichincha. Tanto el mercado privado como el Estado asisten a estos fenómenos con la aplicación de una normativa particular que fomenta unas condiciones especiales para el área.

\section{Análisis de proyectos}

Las nuevas demandas, en función de los cambios económicos y normativos, generan modificaciones de los diferentes submercados y la incorporación de otros. Esto da cuenta de la gran dinámica y heterogeneidad del espacio urbano. Allí las pautas y regularidades espaciales no responden en principio a la normativa estatal, sino que son generadas por las convenciones sociales del conjunto de los habitantes de una ciudad. La población ubicada en distintas zonas, hace que los inmuebles sean usados para ciertas actividades y funciones, diferenciándose de los que se encuentran en otras áreas. Es esta pauta colectiva lo que promueve la posibilidad de un uso colectivo de la ciudad (Jaramillo, 2009, p. 307).

La comercialización se presenta en forma variada sobre el Frente de Renovación Urbana en los últimos ocho años. El mercado residencial es el predominante y está orientado principalmente a los sectores de ingresos altos y medio-altos a través de la construcción de edificios y torres de "alta gama". Las edificaciones cuentan con una gran división entre los espacios para ser habitados y los lugares de servicios y amenities. La proporción de estos últimos, en relación a la vivienda es lo que encarece $y$, a la vez, aporta la diferencia con el resto de los edificios.

El mercado comercial es el segundo en importancia, se caracteriza por pequeñas oficinas (inmobiliarias, estudios de arquitectura, diseño, jurídicos y contables, agencias de turismo, sedes administrativas de empresas, etc.) mientras que las grandes corporaciones apuntan al futuro Puerto Norte (sector aledaño a Pichincha). Asimismo, se encuentran locales vinculados al entretenimiento nocturno (boliches, pubs y discotecas) y otros pocos orientados al rubro gastronómico.

Por último, el mercado industrial ha ido disminuyendo en Pichincha debido a los altos precios de los inmuebles y posteriormente, a la sanción de la Ordenanza $\mathrm{n}^{\circ}$ 8. I25/07. La normativa no admite las actividades vinculadas con industrias y depósitos de cualquier tipo teniendo como intención cambiar la funcionalidad del sector. Los pocos locales industriales que continúan en la costa del barrio poseen permisos de habilitación anteriores a la sanción de la preceptiva.

A lo largo del período de estudio, el Frente de Renovación Urbana ha sufrido diversas transformaciones edilicias. Entre los años 2003 y 2005 no se registran permisos de edificación. Sin embargo, a partir del 2006 comienza a incrementarse el volu- 
men construido, obteniendo el valor más alto en el 2007 (siete mil $87 \mathrm{~m}^{2}$ ). Luego comienza a descender hasta el 2010. Los permisos de demolición poseen una evolución más constante entre los años 2004 y 2009 con una superficie promedio de $220 \mathrm{~m}^{2}$.

Cabe señalar que se encuentran además presentados en la Dirección General de Obras Particulares y (o) Programa de Actualización Normativa (para proyectos con condiciones especiales), expedientes de edificación y demolición que todavía no han obtenido los permisos correspondientes. Tal es el caso de los dos proyectos de torres que en breve serán aprobados y modificarán notablemente la evolución de las superficies construidas, superando los mayores índices alcanzados en el año 2007 (ver gráfico 2).

Es en el contexto de este aumento de permisos de edificación cuando se pone en marcha la normativa inherente al cobro de una contribución por mayor aprovechamiento en altura. Este hecho coloca al Estado como actor capaz de retener aquellas mayores ganancias que se producen sin esfuerzo alguno del propietario y como resultado del esfuerzo de la colectividad. Este mayor aprovechamiento en altura repercute sobre el valor del suelo y es sobre ese factor donde el Estado apunta a actuar.

El propietario accede a la captación privada de ganancias extraordinarias que no surgen de su propio esfuerzo sino de la aplicación de una normativa que le posibilita ese mayor aprovechamiento del suelo (por construcción en altura). Sin embargo, corresponde retribuir al Estado, al menos en una parte del incremento del valor, considerando que el beneficio extraordinario encuentra su origen en el colectivo.

\section{Conclusiones}

La sanción de una normativa puede modificar el ciclo de la inversión inmobiliaria dando lugar a la aparición de nuevos usos, en pérdida de los emprendimientos tradicionales. El Estado, como regulador de las actividades urbanas, tiene la capacidad de orientar la intensidad de la construcción en cada terreno. En este sentido, la modificación de los índices de edificación tiene consecuencias directas en la valorización de los terrenos. De la misma forma, los movimientos en los precios del suelo posibilitan la especulación.

En el caso de Pichincha, las sobreganancias se dieron por factores externos (que hicieron que los terrenos actúen como un activo financiero) y por el desarrollo de distintos emprendimientos. La especulación se procuró tanto en lo que se define como protoespeculación, tendencia creciente de los precios de suelo a partir del 2003, como en términos de especulación pasiva, donde los inversores compran los terrenos o inmuebles antes que incrementen su valor (del 2000 al 2003 y (o) 2004), esperando el tiempo necesario para que se produzca la valorización. Pero también hay presencia de especulación inductiva, que se produce cuando los agentes productores desarrollan porciones de espacio urbano, apuntando a que de esa forma se inicie un proceso de cambio de usos e intensidades en determinados lugares de la ciudad.

En consecuencia, se modificaron los tipos de renta que soportan los terrenos e inmuebles. En primer lugar, la renta absoluta urbana que está presente en todos 
los terrenos urbanos. En segundo término las rentas primarias en sus dos clases: diferencial tipo I (localización de nuevas edificaciones al noroeste del barrio) y diferencial tipo II (por la construcción de edificios en altura). Finalmente, los inmuebles sostienen una de las rentas secundarias, siendo la más elevada la renta diferencial de vivienda, mientras que la renta diferencial de comercio se manifiesta sobre algunos sectores como en la avenida Ovidio Lagos o la calle Salta. Por otro lado, la renta diferencial industrial está desapareciendo lentamente debido a la restricción normativa.

En particular sobre el área de estudio de este trabajo es factible que con la futura construcción de las torres se va a impulsar una transformación muy importante. Los pocos galpones que quedan irán cediendo lugar al ser reemplazados por estos nuevos prototipos edilicios. Por lo tanto, a los antiguos propietarios les va a convenir vender su lote para que se construya en altura. Al respecto la secretaria de planeamiento de la Municipalidad de Rosario, la Arq. Mirta Levin expresa que:"(...) el abastecimiento de infraestructura no va a colapsar en el área dado que cuenta con la planta potabilizadora y la central de energía. Sumado a eso se va actualizar con las obras de Puerto Norte. En consecuencia la infraestructura está garantizada (...)".

En síntesis, habiendo pasado más de tres años de la sanción de la Ordenanza $n^{\circ} 8.125 / 07$, a partir de lo analizado en el presente artículo y con la intención de orientar las reflexiones finales, se exponen los siguientes supuestos:

a) La construcción en el Frente de Renovación Urbana se ha activado con la sanción del Plan Especial Barrio Pichincha.

b) La normativa promulgada, al aumentar los índices de edificabilidad en el FRU, provoca el aumento del valor de los terrenos.

c) La sanción de la Ordenanza n ${ }^{\circ}$ 8.125/07 abre un nuevo ciclo en la inversión inmobiliaria, dando lugar a la aparición de otros usos, en pérdida de los antiguos emprendimientos sobre la costa.

d) Los nuevos prototipos no van a competir con el Proyecto de Puerto Norte, generando una transformación integral del sector.

e) Las tipologías edilicias propuestas para el FRU son factibles, ya que se verificaron previamente para el estudio de la normativa.

Sin embargo, para obtener reflexiones más certeras, dado el poco tiempo transcurrido de la aplicación del instrumento de captación de plusvalías, deberíamos contar con otros datos. Por ejemplo cuáles son los proyectos que se están aprobando, qué superficies tienen, cuáles son los inconvenientes para obtener el permiso, cuál es la recaudación obtenida por la aplicación del canon. Con esas referencias se podrían evaluar las consecuencias a futuro de la aplicación de la norma, así como obtener resultados cuantitativamente más certeros sobre las diferentes rentas en juego.

Resta mencionar que el caso particular da cuenta del rol fundamental que adquiere el Estado en su calidad de actor en las dinámicas -territoriales, espaciales, económicas y sociales- encontrando su fundamento en el entramado urbano, modificándolo y delineando procesos específicos que promueven cambios. Dichas 
transformaciones en sí mismas poseen el potencial de ser instrumentos que viabilicen ciudades cuyo crecimiento, desarrollo y planificación no se encuentre orientado netamente por la lógica mercantil. La experiencia sabe servir de ejemplo para otros casos en América Latina, en particular el chileno, donde no se evidencia una trayectoria en el sistema de capturas de plusvalías. En este sentido, puede auxiliar en el proceso de reconstrucción posterremoto y los planes reguladores que se encuentran en desarrollo.

\section{Bibliografía General}

Barenboim, C. (2010). Formulación y gestión del Plan Especial Barrio Pichincha. I Jornada Internacional sobre Derecho Urbanístico y Gestión del Suelo, Rosario, 15-17 abril.

Bervejillo, F. (2005). Algunas definiciones para la formación en ordenamiento territorial.VI Encuentro de Posgrados Iberoamericanos sobre Desarrollo y Políticas Territoriales, Toluca, 19-2I septiembre.

De Mattos, C.A. (2004).“'De la planificación a la governance: implicancias para la gestión territorial y urbana”. Revista Paranaense de desenvolvimiento, I ( I07), pp. 9-23.

Dócola, S. y Múgica, M. L. (2006). Miradas históricas y espaciales para el Plan Especial Pichincha de Rosario. IV Jornadas Nacionales Espacio, Memoria e Identidad, Rosario, 4-6 octubre.

Furtado, F. (2000). "Repensando las políticas de captura de plusvalías para América Latina”. LandLines, I 2 (3), pp. 6-I0.

Jaramillo, S. (1994). Hacia una teoría de la renta del espacio urbano. Bogotá: Ediciones Uniandes.

Jaramillo, S. (2003). Los fundamentos económicos de la participación en plusvalías. Buenos Aires: Instituto Lincoln de Políticas de Suelos.

Jaramillo, S. (2009). Hacia una teoría de la renta del suelo urbano. Bogotá: Ediciones Uniandes.

Lipietz,A. (1974). Le Tribut Foncier Urbain. París: Maspero.

Topalov, C. (1979). La urbanización capitalista. México: Editorial Edicol.

Smolka, M. O. y Amborsky, D. (2000). Captura de plusvalías para el desarrollo urbano: una comparación interamericana. Instituto Lincoln de Políticas de Suelos. Recuperado 30 de junio de 2010, de: www.lincolninst.edu/searchresults.asp.

\section{Normativas municipales}

Código Urbano de la Ciudad de Rosario (1968).

Plan Urbano Rosario 2007 - 2017 (Anteproyecto de Ordenanza).

Ordenanza $n^{\circ}$ 8.125/07: Plan Especial Barrio Pichincha.

Ordenanza $n^{\circ}$ 7.799/04: Régimen especial para la autorización de mayor aprovechamiento por incremento de altura.

\section{Relevamientos de precios del suelo y permisos de edificación}

Bosch, A; Picasso, J. y otros (2005 y 2006). Guía de tasaciones, actualización 2005 y 
2006. Rosario: Editorial San Patricio.

Dirección de Obras Particulares (2010). Permisos de edificación y demolición. Período 2003-2010, Municipalidad de Rosario. Recuperado 30 de junio de 2010, de: www.rosario.gov.ar/tramitesonline.

Diario La Capital (2003 - 20I0). "Relevamiento del barrio Pichincha”, suplemento de clasificados de inmuebles. Abril y mayo. Rosario: La Capital.

Planos, tablas y gráficos

Plano I. Sectorización del Plan Especial

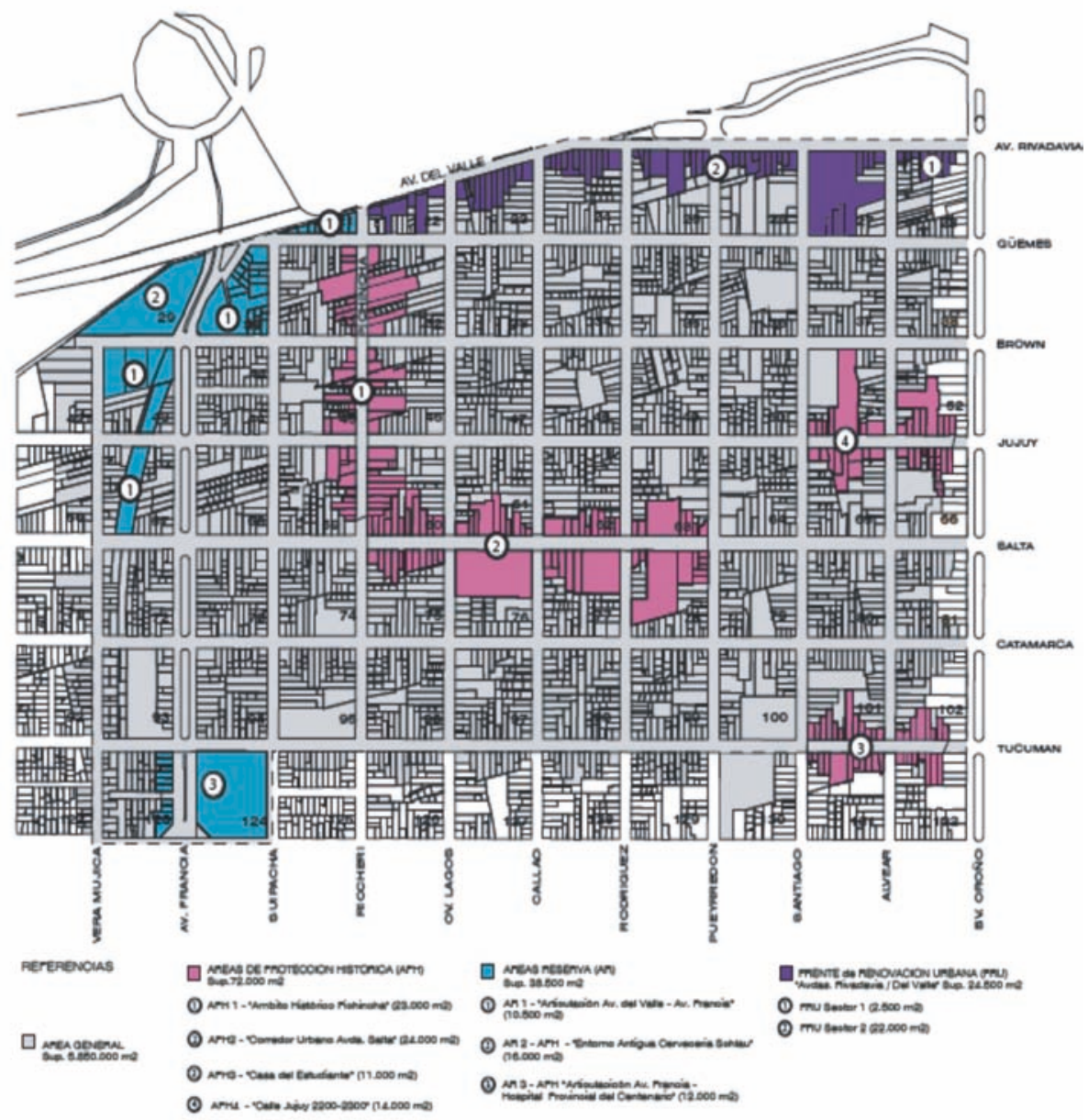

Fuente: Elaboración propia según la Ordenanza N 8.I25, 2010. 


\section{Tabla I. Marco regulatorio interventor en el FRU.}

\begin{tabular}{|c|c|c|}
\hline Normas & Autoridades & Caracterización y niveles de decisión \\
\hline $\begin{array}{l}\text { Código Urbano } \\
\text { de la ciudad de } \\
\text { Rosario (1968) }\end{array}$ & $\begin{array}{l}\text { Secretaría de Planeamiento } \\
\text { Secretaria:Arq. Levin, Mirta } \\
\text { Subsecretario: Ing. Álvarez, Raúl }\end{array}$ & $\begin{array}{l}\text { El Código Urbano es el principal instrumento } \\
\text { de la ciudad. } \\
\text { La Secretaría de Planeamiento } \\
\text { establece las disposiciones } \\
\text { generales de a uso y división de la tierra, área } \\
\text { edificable, destino y alturas de edificación. }\end{array}$ \\
\hline $\begin{array}{l}\text { Ordenanza } \mathrm{N}^{\circ} \\
8.125 / 07 \\
\text { Plan Especial } \\
\text { Barrio Pichincha }\end{array}$ & $\begin{array}{l}\text { Secretaría de Planeamiento } \\
\text { Dir. Gral. Ordenamiento Urbano } \\
\text { Director:Arq. Barese, Pablo } \\
\text { Programa Actualización Normativa } \\
\text { Directora:Arq. Noya, Alicia } \\
\text { Programa Preservación y } \\
\text { Rehabilitación de Patrimonio } \\
\text { Directora:Arq. Fernández, María }\end{array}$ & $\begin{array}{l}\text { El Plan Especial es de carácter intermedio } \\
\text { modifica indicadores urbanísticos del Código } \\
\text { Programa la transformación física y funcional en } \\
\text { Pichincha, el conjunto de parcelas y los ámbitos } \\
\text { públicos interviniendo distintas áreas } \\
\text { de la Secretaría de Planeamiento. }\end{array}$ \\
\hline $\begin{array}{l}\text { Ordenanza } n^{\circ} 7.799 / 04 \\
\text { Régimen especial } \\
\text { para la autorización de } \\
\text { mayor aprovechamiento } \\
\text { por incremento de } \\
\text { altura }\end{array}$ & $\begin{array}{l}\text { Secretaría de Planeamiento } \\
\text { Programa Actualización Normativa } \\
\text { Directora:Arq. Noya,Alicia } \\
\text { Dirección Gral.Tramitación y } \\
\text { Fiscalización Urbanística } \\
\text { Directora:Arq.Ambroggi, Beatriz }\end{array}$ & $\begin{array}{l}\text { El Régimen especial para mayor uso de altura es } \\
\text { una norma particular y específica. El Programa } \\
\text { de Actualización Normativa de la autorización a } \\
\text { propietario del lote ubicado en el Frente de Reno- } \\
\text { vación Urbana. Para ello presenta la propuesta de } \\
\text { adecuación del edificio con el entorno y recibirá } \\
\text { a cambio las recomendaciones pertinentes. E } \\
\text { cálculo de la contribución sobre el excedente au- } \\
\text { torizado esta a cargo de la Dirección General de } \\
\text { Tramitación y Fiscalización Urbanística. }\end{array}$ \\
\hline
\end{tabular}

Tabla 2. Valores promedio base de terreno tipo de $8,66 \mathrm{~m} \times 25 \mathrm{~m}$ (US\$/m²). Período 2003-20I0.

\begin{tabular}{|c|c|c|}
\hline Año & US\$ $/ \mathrm{m}^{2}$ & Cantidad \\
\hline 2003 & 300 & 9 \\
\hline 2004 & 450 & 8 \\
\hline 2005 & 580 & 9 \\
\hline 2006 & 630 & 9 \\
\hline 2007 & 700 & 7 \\
\hline 2008 & 740 & 5 \\
\hline 2009 & 780 & 5 \\
\hline 2010 & 800 & 4 \\
\hline \multicolumn{2}{|c|}{ Total muestra } & 57 \\
\hline
\end{tabular}

Fuente: Elaboración propia sobre avisos del diario La Capital y Guía de Tasaciones Anuales. 
Tabla 3. Relación entre los permisos de edificación y demolición. Período-2003-20I0.

\begin{tabular}{|l|r|r|r|r|}
\hline \multirow{2}{*}{ Año } & \multicolumn{3}{|l|}{ Edificación } & \multicolumn{2}{l|}{ Demolición } \\
\cline { 2 - 5 } & Cantidad & \multicolumn{1}{c|}{ Superficie } & \multicolumn{1}{c|}{ Cantidad } & \multicolumn{1}{c|}{ Superficie } \\
\hline 2003 & 0 & 0 & 0 & 0 \\
\hline 2004 & 0 & 0 & 2 & 606 \\
\hline 2005 & 0 & 0 & 2 & 225 \\
\hline 2006 & 1 & 1.604 & 2 & 300 \\
\hline 2007 & 3 & 7.087 & 2 & 450 \\
\hline 2008 & 2 & 2.010 & 0 & 0 \\
\hline 2009 & 1 & 985 & 1 & 400 \\
\hline $2010 *$ & 2 & 1.145 & 0 & 0 \\
\hline Total & 9 & 12.831 & 9 & 1.981 \\
\hline
\end{tabular}

* Datos de permisos de edificación y demolición relevados hasta el 30 de junio del 2010.

Fuente: Elaboración propia según datos de la Dirección General de Obras Particulares, 2010.

Gráfico I. Evolución de los valores base de terreno tipo de 8,66 m x 25 m (US\$/m2), Período -2003-20I0.

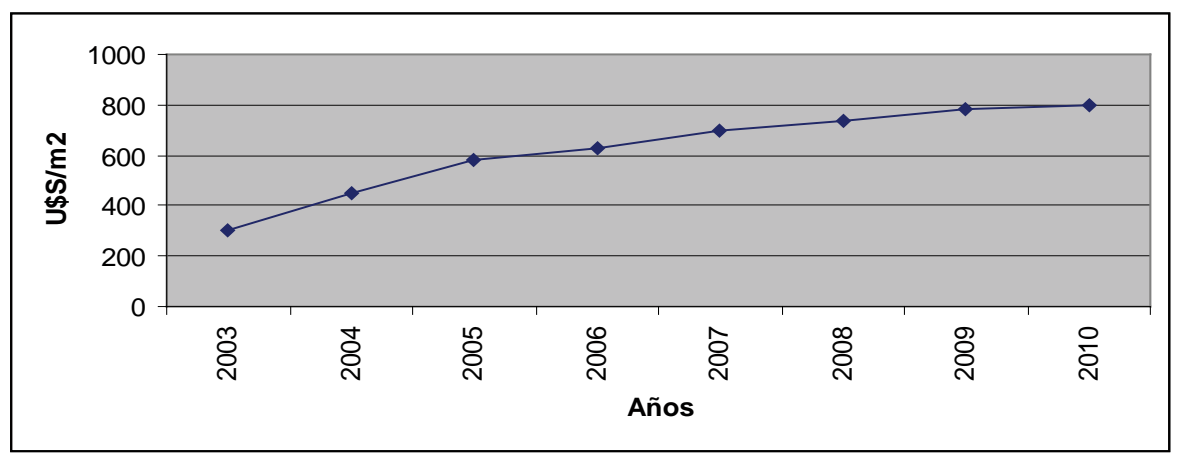

Unidades analizadas: 9 (2003), 8 (2004), 9 (2005), 9 (2006), 7 (2007), 5 (2008), 5 (2009) y 4 (20I0).

Total unidades: 56 (2003 a 20I0).

Fuente: Elaboración propia sobre avisos del diario La Capital y Guía de Tasaciones Anuales. 


\section{Gráfico 2. Evolución de las superficies de los permisos de edificación y demolición. Período -2003-20I0.}

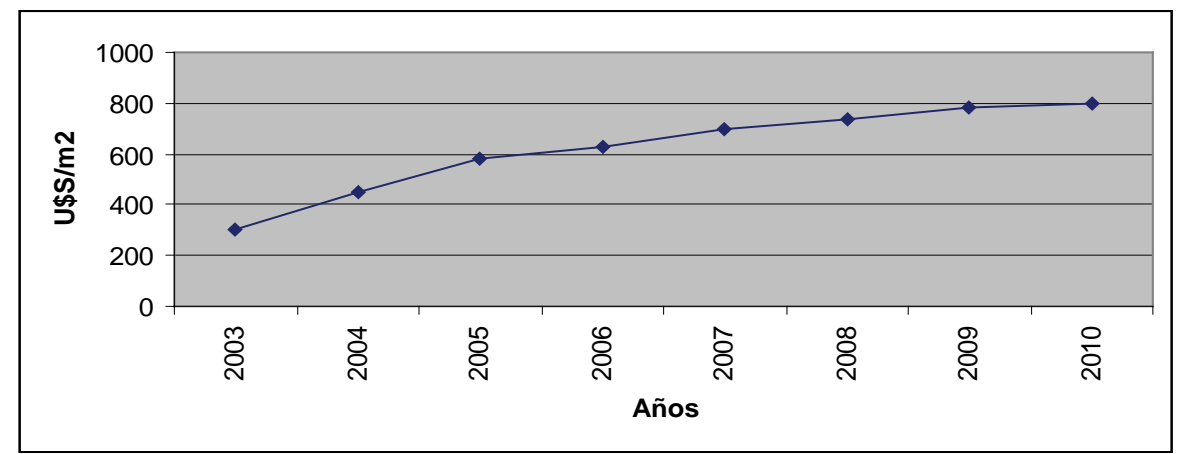

Cantidad de permisos de edificación: 0 (2003), 0 (2004), 0 (2005), I (2006), 3 (2007), 2 (2008), I (2009) y 2 (2010). Total permisos de edificación: 9 (2003 a 20 I0).

Cantidad de permisos de demolición: 0 (2003), 2 (2004), 2 (2005), 2 (2006), 2 (2007), 0 (2008), I (2009) y 0 (2010). Total permisos de demolición: 9 (2003 a 2010).

Fuente: Elaboración propia según datos de la Dirección General de Obras Particulares, 2010. 